\title{
Las variedades del español de Perú: un estudio desde la dialectología
}

\author{
Johnny Fallas Monge \\ Facultad de Filosofía y Letras \\ Universidad Nacional, Costa Rica \\ johnny.fallas.monge@una.cr \\ María de los Ángeles Sancho Ugalde \\ Centro de Estudios Generales \\ Universidad Nacional, Costa Rica \\ maria.sancho.ugalde@una.cr
}

\begin{abstract}
Resumen
El presente artículo describe la variación en todos los niveles de la lengua: fonético-fonológico, morfosintáctico, léxico y sociolingüístico del español de Perú. Para ello, este estudio se basa en un estado de la cuestión, principalmente, desde la dialectología; no obstante, incluye datos históricos, sociales y del contacto de las lenguas indígenas quechua y aimara con el español, todos estos aspectos contribuyen en la conformación del habla peruana. Los estudios bibliográficos y descriptivos, como el presente, tienen el propósito de revitalizar las lenguas indígenas, dado el riesgo de su extinción; con ello se pretende salvaguardar el patrimonio lingüístico y cultural de América.
\end{abstract}

Palabras clave: el español de Perú, la variación fonética - fonológica, morfosintaxis, léxico y sociolingüística.

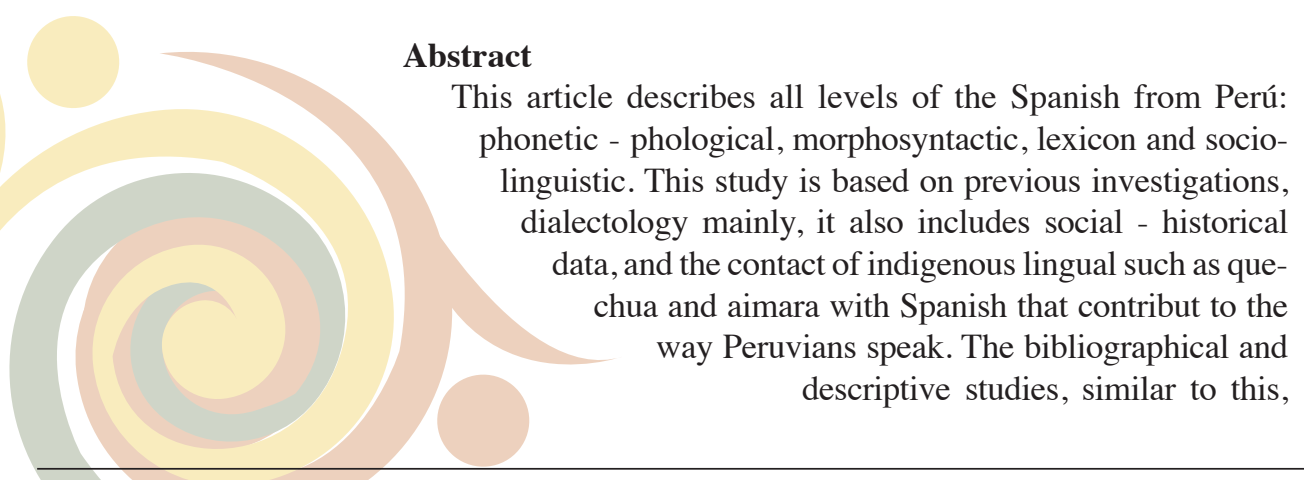


have the purpose of revitalizing the indigenous languages, due to the risk of extinction. With this description we pretend to safeguard the linguistic and cultural patrimony of America.

Keywords: Spanish from Perú, phonetic - phonological variation, morphosyntaxis, lexicon and sociolinguistics.

\section{Introducción}

Desde una perspectiva humanista, el lenguaje es el medio que hace posible los logros culturales de la humanidad; este conserva y revela la herencia de su cultura, es junto con las palabras como se comunican conocimientos, creencias, valores e ideales de la comunidad de habla a la que se pertenece. La lengua expresa cómo el grupo ha percibido, interpretado y concebido el mundo; es decir, las personas se apropian mentalmente del universo por medio del lenguaje.

La lengua conduce todas las experiencias vitales de las personas; las palabras llenan de contenido significativo la vida, imposibles de ser apropiadas interiormente por hablantes que no pertenezcan a una comunidad lingüística determinada (rasgos de identidad). El habla revela el modo de ser del pueblo, su sentido de vida, ahí están difundidas sus actitudes, su ideología y sus aspiraciones; todo lo anterior se revela en su vocabulario, en los rasgos morfológicos y sintácticos, en su pronunciación y entonación, en este caso específico, del ser peruano.

Para ello, se explora la existencia de diversas teorías sobre el origen del español americano, el cual se distingue del peninsular debido a la variación que presenta en todos los niveles de la lengua: fonético-fonológico, morfosintáctico, léxico, sociolingüístico y pragmático-discursivo.

La primera de estas teorías es la Andalucista, apoyada por muchos autores (Lapesa, Guitarte, Enguita, entre otros), quienes afirman que en el proceso de conquista y colonización de América por parte de la Corona Española, se trasladó gran cantidad de colonizadores de origen andaluz; además, existe documentación de la época donde aparecen rasgos coincidentes; dos fenómenos atribuibles al influjo andaluz refieren, principalmente, al seseo y al yeísmo.

Contraria a la anterior, se encuentra la Teoría Indigenista, en la cual se postula la influencia de sustrato indígena, debido a distintas razones: primero, los colonizadores españoles se vieron obligados a incorporar léxico indígena al español para poder explicar la nueva realidad americana, distinta de la europea, en lo referente 
a cuestiones concretas, como por ejemplo: la flora, la fauna, la alimentación y los utensilios domésticos (vocablos como canoa, cacique, aguacate, yuca, papa, entre otros); segundo, a muchos indígenas se les enseñó el español para que sirvieran como intérpretes y así pudieran ser evangelizados, pues la colonización y catequización eran una misma empresa. Además, muchos españoles aprendieron las lenguas indígenas, especialmente misioneros, para poder catequizarlos.

Otra teoría es la influencia del afronegrismo en el español americano, debido a la comercialización de esclavos africanos, de los cuales algunos eran trasladados por los portugueses a España y luego embarcados a América; otros, eran traídos directamente desde África, estos últimos aprendían un pidgin de base española para la necesaria comunicación. No obstante, muchos autores atribuyen las características del español afroamericano a un aprendizaje primitivo del español.

Debido a la confluencia de las teorías descritas, De Granda (1994) propone la Teoría de la Koineización:

La comparación con otras situaciones histórico-lingüísticas homólogas en las que se han producido casos semejantes de coexistencia, prolongada e íntima, de variedades dialectales mutuamente inteligibles de una lengua común e, incluso, de modalidades idiomáticas diferentes, bien sea como consecuencia de expediciones colonizadoras o por otras causas, demuestra que las mismas han desembocado, salvo raras excepciones, en procesos de koineización multidialectal y, en casos menos frecuentes, también en procesos de koineización multilingüística. (p. 24)

Dicha teoría consiste en un proceso que, según este autor, se presentó en América debido al influjo de muchas lenguas y dialectos de origen ibérico; de España, por ejemplo, provenían colonizadores de diversos lugares que hablaban dialectos distintos, en mayor número de Andalucía, Extremadura y Canarias; en América, se encuentran con un gran número de lenguas indígenas, las cuales eran mutuamente ininteligibles entre ellas; además de la presencia en América de esclavos africanos, con la posible influencia de las lenguas africanas. Con base en el anterior contexto, De Granda postula la Teoría de la Koineización, en la cual el español pasa por dos procesos, el de nivelación y simplificación, donde se eliminan elementos complejos de la lengua, ejemplo de ello: la simplificación consonántica y vocálica, y el de la reducción del sistema de conjugación verbal.

En conclusión, muchas de las situaciones y de los rasgos descritos se encuentran en las diversas zonas dialectales de América y, especialmente, se van a estudiar en Perú, por ser el objetivo de ese estudio. 


\section{Historia externa y aspectos sociales}

\section{El Virreinato de Perú:}

Haring (1990), en su libro El imperio español en América describe la organización del Virreinato de Perú en América del Sur como un área mayor que su contraparte norteamericana, la cual abarcaba todo el continente, excepto el Brasil portugués, las Guayanas y la costa caribeña de Venezuela. A pesar de que fue creado una década después del Virreinato de La Nueva España, fue considerado como la más importante de las dos jurisdicciones, durante dos años:

Perú aparecía como la más preciosa de las posesiones americanas de la corona, la fuente de la mayoría de sus riquezas. Muchos de los virreyes habían ocupado previamente el puesto de virrey de la Nueva España, y el traslado de la ciudad de México a la ciudad de Lima se consideraba como el último paso en la jerarquía imperial. (Haring, 1990, p. 121)

La preeminencia del Perú para los españoles se debía a la profusión de sus minas de oro y de plata a través de las cordilleras de Los Andes; desde la parte norteña de la actual República de Perú hasta el sur de Chile y las fronteras de Argentina, los depósitos de plata eran abundantes y los aborígenes los habían explotado, como atestiguan los inmensos depósitos de ornamento de plata y utensilios que Pizarro y sus compañeros tomaron en la conquista del Imperio Inca.

El gran virreinato sureño en el siglo XVI abarcaba el reino del Perú (o Nueva Castilla, como se llamó en los primeros tiempos de La Conquista) junto con los reinos de Panamá, Nueva Granada y Quito, hacia el norte, Chile y Charcas, incluyendo el área del río de La Plata, al sur. El virrey mismo gobernaba directamente sobre la región central del Perú, como presidente, gobernador y capitán general. También era gobernador de las dos jurisdicciones aledañas de Quito y Charcas, cuando fueron organizaciones separadas. El primer virrey fue Blasco Núñez Vela, quien salió de España en 1544 con un mandato especial de ejecutar en Perú las nuevas leyes, las cuales tenían la intención de abolir la servidumbre india. Con él llegó el primer tribunal que se estableció en América del Sur, la audiencia virreinal de Lima. Después, toda América del Sur española fue colocada bajo su jurisdicción, excepto Nueva Granada y los asentamientos de la costa caribeña, los cuales quedaron relacionados con Santo Domingo (Haring, 1990, pp. 122-123). 
En cuanto a la organización territorial española en América del Sur, durante los tres siglos de historia colonial, Haring (1990, pp. 136-137) apunta que se inició con el régimen de un solo virrey sobre un área que hoy cubre ocho grandes repúblicas; gradualmente, surgieron jurisdicciones nuevas e independientes dentro de la unidad anterior, hasta el final del siglo XVIII, cuando el antiguo Virreinato de Perú quedó confinado a los límites ocupados por la moderna república del mismo nombre; el resto del continente quedó establecido en nuevos virreinatos o capitanías generales independientes. Sin embargo, gran parte del prestigio histórico de los virreyes del Perú se preservó; las viejas familias de Perú estaban relacionadas más estrechamente con la aristocracia de España, por matrimonio y simpatía, que los habitantes de cualquier otra colonia. Perú fue la última de las comunidades sudamericanas inducida a renegar de su lealtad a la Corona de España.

\section{Aspectos sociales: multilingüismo del Perú}

En cuanto a la situación de multilingüismo en el Perú, Malmberg en su libro La América Hispanohablante (1970) atribuye este hecho al legado cultural y lingüístico indígena en Perú, país de importancia principal en la Sudamérica de los tiempos coloniales. El Imperio Inca se levantaba sobre la sumisión de una serie de pueblos y tribus de lengua y cultura distintas a las de los quechuahablantes. La costa al sur y al norte de la actual Lima estaba habitada por pueblos que solo tras la expansión incaica, posterior al siglo XI, pasaron a formar parte del Imperio.

Por lo descrito, la cultura indígena de toda el área andina de Bolivia y Perú tenía tal fuerza, y los indios han continuado siendo tan numerosos, que ello ha tenido consecuencias duraderas en el ámbito lingüístico y cultural de la zona. En los Andes Peruanos, el quechua sigue siendo la lengua de gran parte de la población; incluso, se emplea en escuelas e iglesias para la enseñanza o la predicación religiosa. No obstante, con la caída del Imperio Inca y Lima convertida en sede virreinal española, fue centro cultural. La población española crecía constantemente por los refuerzos humanos que enviaba la metrópoli, así la tradición linguística del español de los conquistadores se impuso (Malmberg, 1970, pp. 137-139).

Por su parte, Martínez (1998) afirma que Perú es uno de los países que, en la actualidad, cuenta con mayor contingente de población autóctona, hablante de alguna lengua amerindia (principalmente, el quechua y el aimara), lo que permite visualizar que no solo han conservado su lengua sino también sus costumbres. Sin 
embargo, el ambiente cultural y educativo en pocas ocasiones llega a la población indígena, marginada al mundo rural, carente de derechos y con un frágil poder económico, a lo cual se le debe sumar la existencia del prestigio social en función de la raza y, derivada de este hecho, la clasificación: blanca, mestiza e india.

En consecuencia, desde un punto de vista sociolingüístico, el español asociado a diversos grupos de hablantes, según las zonas dialectales, se caracteriza por determinados factores o rasgos lingüísticos subvalorados o sobrevalorados y desencadenan valoraciones que pueden ser positivas o negativas; en este último caso se habla de un hecho estigmatizado (Caravedo, 1990, p. 35).

\section{Estado de la cuestión}

\subsection{División de zonas dialectales del Perú}

Lipski (1994, p. 338), basado en variables etnolingüísticas y geográficas, divide Perú en dialectos costeros, dialectos de las tierras altas ${ }^{1}$ y de la cuenca amazónica. La costa, la subdivide en norte (hacia la frontera con Ecuador), central (zona de Lima/ Callao) y extremo sur (cerca de la frontera chilena).

Por su parte, Caravedo 2 , citado en Alvar (2000) afirma que los diferentes tipos de asentamiento demográfico favorecieron el desarrollo paralelo de dos modalidades dialectales muy definidas: la costeña, en las áreas de concentración hispánica, y la andina, en las zonas mayoritariamente indígenas, en la situación de contacto de lenguas. El área de la selva o amazonia fue de muy tardía colonización y su historia social y lingüística ha sido poco estudiada. Se puede aludir a una variedad amazónica desarrollada, en contacto con un amplio espectro de lenguas de muy variada tipología, de cuya influencia sobre el español se conoce poco.

1 Malmberg (1970, p. 152) menciona que la diferencia dialectal de Hispanoamérica se ha querido derivar, también, de condiciones climatológicas. En cierta medida hay una coincidencia lingüística entre las zonas bajas, llanas y costeras, por una parte, y las altas mesetas de Perú, Bolivia y Méjico, por otra. Se consideran clima y naturaleza como factores que influyen de manera importante en la estructura social de una región dada. El hecho de que las comarcas agrícolas de los países bajos de América hayan atraído grupos de población del mismo tipo de aquellas a las que pertenecen los jornaleros de los llanos andaluces no es, quizá, incomprensible.

2 Rocío Caravedo es quizá la más prolífera investigadora del español de Perú y citada por muchos otros autores como Quesada Pacheco (2000), Fontanella de Weinberg (1993) y Vaquero de Ramírez $(1995,1998)$, entre otros. 


\subsection{Variación en el nivel fonético-fonológico}

En el nivel fonético-fonológico se encuentra la mayor cantidad de estudios acerca del español hablado en Perú. Los siguientes rasgos representan la pronunciación peruana:

Oposición de /N/, /y/: según Lipski (1994, p. 340) la mayoría de los dialectos andinos del Perú conservan la lateral palatal $/ N /$ en oposición a $/ \mathrm{Y} /$, la primera se pronuncia como lateral, la segunda como una fricativa débil. Pero, por influencia del quechua, los hablantes bilingües pueden presentar una pronunciación fricativa rehilada de / $/$. Este último proceso, Caravedo citado en Alvar (2000) lo describe para la zona amazónica como una diferenciación entre una no lateral fricativa y relajada /y/ y una no lateral, sea africada o fricativa rehilada /ž/ en el habla del mismo individuo, donde se entrecruzan los contextos.

Sobre el mismo fenómeno, Caravedo citado en Alvar (2000), afirma que en Perú se presentan las dos posibilidades funcionales respecto de las palatales; por un lado, la diferencia entre lateral y no lateral y, por otro, su indiferenciación en el yeísmo. La diferenciación de $/ \widehat{\Lambda}$ y $/ \mathrm{y} /$ se encuentra en los hablantes de las zonas andinas; sin embargo, para esta autora el rasgo no es consistente, pues se alternan los dos patrones en el habla de un solo informante, lo que revela la progresiva pérdida de la diferencia, más evidente en la confluencia de grupos en Lima.

Yeísmo: La fusión de / $/$ / con / $/ \mathrm{y} /$ es habitual en las tierras del norte de Perú, principalmente, entre los hablantes urbanos más cultos (De la Puente-Schubek citado en Lipski (1994). Con respecto a la zona de Lima, Lipski (1994, p. 342) menciona que posee un "estatus dual" por sus características históricas de antigua capital del virreinato español y principal puerto comercial durante la época colonial; en consecuencia, su fonética refleja dicha dualidad por medio de una estratificación social.

Lima y toda la costa peruana es yeísta, es decir, no conserva el fonema lateral palatal $/ N /$ y la $/ \mathrm{y} /$ es débil y carece de una ficción audible que puede debilitarse hasta la elisión en contacto con /i/ y /e/, principalmente en el nivel vernáculo. En la costa norte, la /y/ es en especial débil en comparación con Lima. Por su parte, las tierras bajas amazónicas presentan una /y/ intervocálica que es sistemáticamente una africada, a veces desonorizada entre hablantes de lenguas indígenas (Lipski, 1994, p. 344). 
Con respecto a la zona costera yeísta, Caravedo, citado en Alvar (2000), excluye el extremo sur, desde Arequipa hasta Tacna, donde se encuentra la distinción no consistente alternando con la indistinción como parte del proceso de cambio. En la costa central y norte existe una tendencia hacia el debilitamiento articulatorio hasta llegar a la elisión total del segmento en posición intervocálica, al final de la palabra como en "cuchío", "mantequía", incluso en hablantes de clase media.

Velarización de nasales y no nasales: La velarización o elisión completa de la /n/ es un fenómeno que se produce con regularidad en las zonas altas de Perú. En Lima, y en la mayor parte de la costa peruana, se velariza la $/ \mathrm{n} /$ en final de palabra (Lipski, 1994, pp. 341-343). A lo anterior Caravedo, citado en Alvar (2000), afirma que la velarización no solo se presenta en final de palabra, si no también en el interior de esta, sea cual fuese la consonante que la siga: "tanbién", "antes", "ajcho", "aycla", "cansión". Además, las realizaciones velares alternan con una incipiente tendencia hacia la elisión de la nasal, con desplazamiento del rasgo de nasalidad a la vocal contigua, incluso puede afectar a otros segmentos en posición implosiva, como en "dinno" por "digno" o "sinno" por "signo".

En la zona costera Caravedo, citado en Alvar (2000), registra una tendencia marcada hacia la neutralización de las no nasales, con preferencia de la forma velar sonora: "adagtar", "ogservar", "arigmética", extendida a grupos de clase sociocultural superior. En las zonas andinas esa tendencia velarizadora se materializa en la articulación sorda: "doxtor", "axto", "oxservar".

Pronunciación de /č/: En las tierras altas andinas, la /č/ africada en ocasiones se realiza como una fricativa, pero en el caso de Lima la /č/ no suele perder su elemento oclusivo (Escobar, citado en Lipski, 1994).

Vibrantes: Respecto de las vibrantes Caravedo, citado en Alvar (2000), evidencia un fenómeno de neutralización ${ }^{3}$ de estas en posición implosiva; las tendencias en el español de la costa, principalmente, el de Lima, sigue la dirección del debilitamiento manifestado en la producción de variantes fricativas, relajadas y elididas, en especial al final de palabra. Dicha tendencia contrasta con la presencia de variantes asibiladas en las zonas andinas y las amazónicas. La asibilación ocurre en los contextos de la vibrante múltiple, pero también en sílaba implosiva. A veces, alterna con un sonido más débil de tipo retroflejo, que se presenta también en la zona amazónica. En los dos últimos casos descritos, el fenómeno no se encuen-

3 La neutralización es un fenómeno que se conoce como la pérdida de una oposición fonológica distintiva en un contexto fónico determinado. 
tra socialmente estratificado en las zonas originarias; sin embargo, cuando estas modalidades se trasladan a Lima, reciben una valoración socialmente negativa al representar la modalidad andina.

Por su parte, Lipski (1994) afirma que existe una tendencia hacia la pronunciación de la vibrante múltiple /ř/ como fricativa, con mayor intensidad en el sur, desde Cuzco a Puno. En la región andina del norte de Perú es más común la pronunciación como vibrante múltiple. Con frecuencia, en las tierras altas andinas, la /r/ final de sílaba se convierte en una sibilante sorda ante pausa o se produce una fricativa rehilada; pero en Lima la /r/ final de sílaba es una vibrante simple o una fricativa alveolar. Además, puede caer en posición final de sintagma, entre los estratos socioculturales más bajos.

Grupos /tr/, /pr/ y / kr/: Para la pronunciación de la /r/ en estos grupos existe una diferenciación en cuanto a hablantes bilingües y monolingües; entre los primeros, la /r/ es una fricativa o una aproximante retrofleja, mientras que los segundos suelen pronunciar la /r/ como una vibrante simple (Lipski, 1994, p. 341).

Seseo $^{4}$ : Caravedo, citado en Alvar (2000), presenta una diferenciación articulatoria de las sibilantes, agrupadas a partir de tres procesos: primero, el mantenimiento, que se expresa mediante un tipo de "ese" dental en la zona costeña y ápico-alveolar muy tenso en la zona andina. Segundo, el debilitamiento, el cual se expresa a través de la aspiración preconsonántica registrada en la zona de la costa, y especialmente en Lima; en este último lugar, incluso la aspiración llega a la producción de una "jota" ("Cojco" por "Cusco") en las clases media y alta, donde no recibe valoración social negativa. Tercero, la elisión de /s/ o la aspiración prevocálica, común en las zonas caribeñas, constituye una forma estigmatizada de las clases populares. En la variedad amazónica no existen estudios exhaustivos del seseo, pero se puede afirmar que hay una tendencia hacia el mantenimiento, expresada en la ausencia de aspiración en los contextos favorecedores de esta.

Con respecto a la pronunciación de /s/, Lipski (1994, p. 341-343) afirma que en las tierras altas andinas se conserva la /s/ final de sílaba y de palabra como [s]. Además, se combina con la frecuente sonorización de /s/ prevocálica final de palabra. En Lima, en el español de la clase media, la /s/ se convierte en una aspiración en posición preconsonántica, mientras que se conserva [s] sibilante ante

4 Para más detalle sobre este rasgo, véase el artículo "Constricciones contextuales del español hablado en Lima. El caso de /s/" de Rocío Caravedo. 
pausa y vocales en posición inicial de palabra. En el nivel vernáculo de las tierras altas andinas, se produce la elisión de /s/ final en algunos casos, por ejemplo, cuando se ha lexicalizado, como en la usual pronunciación de "entonces" como "entonce".

Las obstruyentes sonoras /b/, /d/ y /g/: Las obstruyentes sonoras se resisten a la desaparición en las tierras altas peruanas; especialmente, entre los hablantes bilingües se conserva la pronunciación oclusiva en los contextos intervocálicos, lo mismo ocurre en las tierras bajas amazónicas (Escobar, citado en Lipski, 1994).

La fricativa posterior / $x$ /: En las tierras altas andinas recibe una fricación audible y es palatal ante las vocales anteriores, mientras que en la costa central y en Lima la / $\mathrm{x} /$ es una aspiración débil, que rara vez posee una fricación velar o postpalatal. En cuanto a las tierras altas amazónicas, la /x/ es una [h] faríngea débil y muchos hablantes de esta zona dan esa misma pronunciación a /f/ (Lipski, 1994).

Reducción de las vocales átonas: En Los Andes Peruanos, principalmente en las provincias del sur, las vocales se reducen hasta llegar incluso a la elisión en contacto con /s/ (Lipski, 1994).

Reducción del sistema vocálico del español: Los hablantes bilingües con poco dominio del español tienden a reducir el sistema español de cinco a tres vocales, fusionando las oposiciones /e/- /i/ y /o/- /u/ por influjo del quechua (Lipski, 1994).

Caravedo, citado en Alvar (2000), define este fenómeno, para las zonas andinas, como la alternancia entre los segmentos /e/, /i/ por un lado y /o/, /u/ por otro, claramente separados en las demás zonas peruanas: "ajé" por "ajî", "octobre" por "octubre", "sigoro" por "seguro". Asimismo, los enlaces vocálicos diptongales, no permitidos en quechua, se disuelven mediante semiconsonantización de una de las vocales, creación de hiato o eliminación de una de las vocales, por ejemplo, "iscuyla" por "escuela", "liyún" por "león", "surti” por "suerte", entrecruzamiento debido al contacto entre el español y el quechua; sin embargo, este fenómeno está muy estigmatizado en el español peruano.

Elisión de /b/, /d/ y/g/ intervocálica: Según Caravedo, citado en Lipski (1994), en la zona dialectal de Lima la /d/ en posición intervocálica se pierde, incluso en los estilos de habla formales; también la /b/ intervocálica cae con frecuencia. En la costa norte, la reducción de las consonantes finales es más pronunciada debido 
a la marginación sociocultural de esta región y a menudo se pierden /b/, /d/ y /g/ intervocálicas (Mendoza, citado en Lipski, 1994).

\subsection{Variación en el nivel morfosintáctico ${ }^{5}$}

Voseo: La existencia y extensión del voseo en Perú es significativa. Los peruanos cultos de las zonas urbanas pueden no haber oído nunca "vos" y a menudo niegan su existencia; sin embargo, se conserva especialmente entre hablantes indígenas (Páez, citado en Lipski 1994. Según Lipski (1994), actualmente el voseo se encuentra en las zonas altas del sur y en la zona del Altiplano (Puno), en partes de Arequipa y zonas de la costa norte, en los niveles sociolinguiísticos más bajos.

Al respecto, Caravedo, citado en Alvar (2000), en sus investigaciones encontró restos de voseo en algunas zonas rurales de la costa norte y sur del Perú, y también de La Sierra; en todos los casos parece tratarse de voseo pronominal y se usan en tratos íntimos y coloquiales.

Pronombres: En el español de América se encuentra una diferencia respecto del paradigma pronominal, debido a la ausencia de vosotros. Según Caravedo, citado en Alvar (2000), no se puede afirmar que la forma vosotros está en su totalidad ausente del español peruano, pues aparece en ciertos contextos claramente delimitados y con un contenido diferente del peninsular. No se trata del plural de tú como forma de tratamiento, sino de una forma plural indiferenciada respecto del tipo de tratamiento, que caracteriza situaciones solemnes o de mucha formalidad como discursos, arengas o sermones.

Selección de los pronombres clíticos: Para Caravedo, citado en Alvar (2000), los pronombres objeto de tercera persona presentan una gran variabilidad en el español peruano. De manera general, la modalidad costeña sigue el llamado "sistema etimológico" el cual supone flexión de número y género en el objeto directo (lo, los, la, las) y solo de número en el indirecto (le, les). Sin embargo, existen alteraciones en el patrón antes descrito, en el caso de secuencias como "se le ve bien" en vez de "se lo ve" o "se la ve", según se trate de masculino o femenino. Además, en verbos como "denominar", "considerar", "llamar”, los cuales suelen usarse con "le" o "les".

5 Una mayor contextualización de la sintaxis peruana se encuentra en Sintaxis Hispanoamericana (1994) de Charles E. Kany. 
Otra forma de alteración de los patrones de concordancia de objeto se manifiesta en la construcción "se los", donde "se" no es la forma impersonal sino el objeto indirecto, por ejemplo, en "se los doy", "lo" adquiere una marca de plural cuando se quiere decir "doy a ustedes un libro" donde debe ocurrir "se lo doy".

Sobre estos mismos fenómenos, Lipski (1994) afirma que es habitual que los clíticos de objeto directo "lo" y "la" se utilicen en contextos que requieren un clítico de objeto indirecto, entre hablantes bilingües con un dominio limitado del español. También, en el español andino bilingüe es común la falta de concordancia entre los clíticos y los objetos directo e indirecto o entre el sujeto y el verbo.

"Él los [les] dio algunas instrucciones"

"A María nosotros lo [la] adoramos"

"Los informes fueron excelente [excelentes]". (Lipski, 1994, p. 345)

Según Caravedo, citado en Alvar (2000), en el español andino se encuentra muy extendido el leísmo y ocurre con gran frecuencia el loísmo, a veces alternando en el mismo hablante o en distintos hablantes de la misma zona. Sin embargo, contrario a Lipski, Caravedo afirma que estos fenómenos no ocurren solo en los hablantes bilingües por influencia del quechua, sino que se extienden también a los monolingües de la misma variedad andina. En todas las esferas sociales utilizan "lo" como la única forma pronominal para indicar la función de objeto, sin diferenciaciones de número ni de género; junto al leísmo, este uso se extiende al español amazónico en zonas no quechuahablantes.

Adverbio intensificador más el superlativo: En las tierras altas andinas, a veces, aparece la combinación de un adverbio intensificador "muy" y el sufijo adjetival superlativo "-ísimo".

“El niño juega muy poquísimo” (Pozzi - Escot, citado en Lipski, 1994, p. 345).

Combinaciones sintácticas: Muchos fenómenos sintácticos andinos que aparecen entre los hablantes con un menor dominio del español poseen influencia del quechua, o en el Altiplano, del aimara, por ejemplo, en cuanto al orden de palabras (objeto + verbo), uso del gerundio y las formas no finitas del verbo: 
- "Comida tengo".

- "De mi mamá en su casa estoy yendo".

- "La puerta sin cerrar nomás me había dormido" (Lipski, 1994, p. 346).

Las construcciones anteriores son calcos del orden de palabras quechuas; algunas de estas han sido utilizadas en los estereotipos populares y literarios del español andino de Perú (cf. Rivarola, 1999 y Martínez, 1998); no obstante, para Lipski (1994) dichas formas son propias solo de los niveles más bajos de fluidez en español.

Duplicación de clíticos: Una característica frecuente en el español andino vernáculo es la duplicación del clítico de objeto directo, incluso cuando el objeto es un sintagma nominal animado o inanimado. En niveles bajos de fluidez, los hablantes utilizan "lo" para todos los objetos directos, independientemente del género o número gramatical.

“No lo encontró a su hijo" (Klee MS, citado por Lipski, 1994, p. 347).

Sin embargo, no se produce la duplicación de clítico cuando el objeto directo ha sido desplazado a la primera posición.

“A la chica [la] he visto en misa” (Escobar, citado en Lipski, 1994, p. 347).

Objetos directos nulos: Son muy frecuentes en las tierras altas de Perú, no así en los dialectos costeros.

“A veces en la noche dejo su quacker ya preparado en la mañana $\emptyset$ caliento y $\emptyset$ toman" (Escobar citado en Lipski, 1994, p. 347).

Posesivos redundantes: Es frecuente la presencia de los posesivos redundantes, atribuida por lo general al español andino, aunque suele presentarse en la modalidad costeña de los grupos bajos y medios, y también en la amazónica, en relación con la tercera persona y no, necesariamente, en casos susceptibles de ambigüedad.

"Su casa de mi mamá" 
"Celebramos su fiesta de la tierra" (Caravedo, citado en Alvar, 2000, pp. 163164)

Es distintiva de esta modalidad la combinación del posesivo con el cambio de orden en secuencia como: "de la señora su sobrina".

Según Lipski, en la región de Los Andes los hablantes emplean dobles posesivos por influencia del quechua, combinan el adjetivo posesivo con un sintagma preposicional encabezado por "de", en el nivel vernáculo:

“Lava su pantalón del niño" (Escobar, citado en Lipski, 1994, p. 348).

Sobre los posesivos, Caravedo, citado en Alvar (2000), agrega la presencia sobrecargada de estos en el español peruano, unida a la de diminutivos, en contextos afectivos a veces referidos a los alimentos: "mi sopita", "tu lechita", e incluso la presencia de posesivos superfluos despersonalizados, por ejemplo, "le pongo su sal", "su pimienta" (a la comida).

Estos usos se encuentran muy extendidos en todos los grupos sociales de todas las áreas geográficas.

Concordancia gramatical: Respecto de la concordancia del eje nominal, las alteraciones de género son notables en las modalidades andina y amazónica, por ejemplo, "el costumbre", "la pie", "mi niñez fue rústico" y han sido estudiadas como consecuencia del contacto entre el español y las lenguas indígenas, carentes de esas variaciones flexivas en su estructura; a la discordancia se une la omisión del artículo. En la zona costera también se presentan algunos casos de discordancia como los descritos (Caravedo, citado en Alvar, 2000).

Sistema verbal: Caravedo, citado en Alvar (2000), afirma que el valor de presente expresa todas las posibilidades extensivas para el sistema español, por lo que en muchos casos se utiliza el presente para referirse a acciones pasadas o futuras; además, se produce la simplificación del paradigma verbal con el uso menos frecuente del modo subjuntivo. En el español peruano, especialmente costeño, se prefieren las formas perifrásticas para el futuro y para el pretérito, en reemplazo de las formas flexionadas.

El futuro se expresa mediante la combinación de la forma flexionada del verbo "ir" con el infinitivo del verbo principal como "voy a ir", "vas a leer" o mediante 
la perífrasis del verbo "estar" con el gerundio: "estoy llegando mañana a las seis". Por otro lado, la forma flexiva del futuro ocurre para expresar duda: "será asî", "estará cansado". Para las formas de pasado se usa con frecuencia el perfecto compuesto en vez del simple, dicha tendencia está muy marcada en la zona costeña del norte, también se presenta en el español andino y el amazónico, principalmente en la primera zona, donde se postula la traslación de valores específicos del sistema quechua en el sistema verbal español.

En relación con el sistema verbal del español peruano, Lipski (1994, pp. 346-348) afirma que el pluscuamperfecto de indicativo se emplea para expresar eventos no conocidos o que no son de la propia experiencia del hablante bilingüe con poco dominio del español, por ejemplo, "habías llegado anoche" para indicar "parece que llegaste anoche". Además, en Perú, un verbo principal en pasado puede ir seguido por un subjuntivo en presente como en la forma "él quería que lo hagamos".

Subordinación: La partícula más utilizada para introducir oraciones subordinadas es "que", independientemente del tipo de función de la subordinada: "la persona que te hablé". La generalización de la función contrastiva de esta partícula, sin acompañamiento preposicional, contrasta con la presencia frecuente del "dequeísmo" en distintos contextos, no solo verbales sino también adverbiales, como en "pienso de que", "opino de que". En relación con los usos peruanos, se podrían presentar en contextos más favorables respecto de los grupos sociales; por ejemplo, existe una mayor tolerancia hacia el dequeísmo, entre los grupos de clase alta, cuanto más alejada se encuentre la preposición del verbo que preside la subordinación (Caravedo, citado en Alvar, 2000, p. 166).

Algunos usos preposicionales y adverbiales: Según Caravedo, (citado en Alvar, 2000, p. 167), los usos de la preposición adquieren distintos matices en el español andino y en el amazónico, principalmente, en construcciones como "en (mi, su) delante", "en (mi, su) atrás". En cambio, en la modalidad costeña se prefieren las construcciones "delante de mío", "atrás suyo" combinadas con la forma "en (mi, su) delante". Además, en el habla andina se suelen combinar los adverbios de lugar con la preposición "en": "estoy en allá", "en aquí", mientras que los objetos circunstanciales de lugar se presentan sin la preposición, como en "voy Lima".

A menudo, los adverbios no se comportan como formas invariables y flexionan en género y número, como en: "medio cansado", "media cansada". Reciben, igualmente, sufijos derivativos como diminutivos y aumentativos: "ahorita", "tempranazo", "rapidito" (Caravedo, citado en Alvar, 2000, p. 167). 


\subsection{Variación en el nivel léxico}

Con respecto a la variación del nivel léxico del español, Vaquero de Ramírez, en su libro El español de América II. Morfosintaxis y léxico (1998), hace una caracterización general acerca de tres componentes importantes en la constitución del léxico hispanoamericano:

a) El patrimonial: adaptado a las nuevas realidades y fuente de las creaciones.

b) El autóctono: adoptado de las lenguas indígenas, generales o particulares.

c) El africano: presente en determinadas zonas, desde la llegada de los esclavos a las costas del Caribe" (Vaquero, 1998, p. 39).

En este sentido, los "americanismos léxicos" agrupan tanto los americanismos exclusivos de Hispanoamérica, ya sean generales o regionales, como los que han alcanzado difusión panhispánica, aunque estos últimos ya no sean considerados como tales por algunos lexicógrafos.

Dentro del léxico patrimonial, Vaquero (1998, pp. 40-42) presenta la adaptación de vocablos a las nuevas realidades a las que se enfrentaban los españoles en América; un ejemplo de ello refiere a las tendencias formativas que abundan en derivaciones del tipo: "palomilla" (muchacho callejero) en Perú. En cuanto al léxico autóctono, fueron muchas las lenguas amerindias existentes en el siglo XV, pero solo pocas dejaron su presencia léxica en el español, una de estas es el quechua, ligada a la importante cultura continental Inca, y que se había convertido, ya en tiempos precolombinos, en lengua general de prestigio y en la actualidad sigue teniendo gran importancia.

El quechua fue una lengua general del imperio incaico, extendido desde la costa del Pacífico hasta los Andes, y desde Ecuador hasta Chile. Esta lengua, viva en la actualidad, cuenta con varios millones de hablantes, en su mayoría bilingües. Junto al quechua, el aimara es otra lengua incaica importante, razón por la que es difícil precisar el origen de algunos indigenismos andinos. Vaquero (1998, p. 46) cita las siguientes voces quechuas más extendidas en América, algunas de difusión general:

6 Vaquero define el término "americanismo léxico" como unidad léxica o valor semántico originado en algún país de América. 
Cancha: "terreno llano"

China: "mujer india o mestiza", "niñera", "amante".

Coca: "planta medicinal".

Cóndor: "buitre americano"

Fotuto: "especie de trompeta de caracola"

Llama: "animal de carga"

Locro: "cierto guisado de carne con papas"

Mate: "infusión de hierba bebida como té"

Ojota: "sandalia de cuero"

Pallar/ payar: "improvisar coplas en competencia con otro pallador"

Voces propagadas por la literatura gauchesca:

Palto: "árbol de aguacate y su fruto, la palta"

Pampa: "llanura".

Papa: "tubérculo comestible"

Poroto: "habichuela"

Puma: "león americano, animal sagrado"

Puna: "tierra alta andina" (Vaquero 1998, p. 46)

Autores como Lipski (1994, p. 349) afirman que la principal fuente de elementos léxicos no hispánicos en el español de Perú es el quechua, y debido a la importancia de este país en el sistema colonial español, muchos vocablos son de uso general en Hispanoamérica. Otros elementos léxicos están presentes solo en la región andina quechua - hablante de Sudamérica y pocos son exclusivos de Perú.

Entre los peruanismos más comunes se encuentran los siguientes:

- Ajiaco: "plato hecho con ajo y patatas"

- Ancheta: "una buena ganga"

- Cancha (blanca): "palomita de maíz"

- Chupe: "tipo de guisado"

- Chacra: "granja pequeña"

- Choclo: "mazorca"

- Concho: "sedimento de café o vino"

- Dormilonas: "tipo de pendientes"

- Escobilla: "cepillo, cepillo de dientes"

- Jebe: "goma"

- Jora: "maíz fermentado para hacer chicha"

- Pisco: "brandy destilado de uvas" (Lipski, 1994, p. 349). 
Por su parte, Agostinho de La Torre (1999, p. 37) afirma que muchos lexicógrafos consideran como "americanismos" todo tipo de voces de procedencia indígena, incluso aquellas que están integradas en el uso peninsular, y esto se debe al hecho de que dichas voces provienen de las diversas lenguas amerindias. Para esta autora, gran número de indoamericanismos han pasado a la lengua general, pero la mayoría sigue siendo de uso exclusivamente americano e incluso limitado a ciertas regiones de Hispanoamérica. Por otro lado, el bilingüismo ha sido, y continúa siendo, un factor importante en la integración de indoamericanismos al español general, por influencia del sustrato indígena. En el caso del español de Perú, se encuentran voces quechuas y aimaras como las siguientes:

\begin{tabular}{|l|l|}
\hline Voces quechuas & Voces aimaras \\
\hline Charqui (derivado de charquecillo) & Carpa \\
Chirimoya & Chuncho \\
Chucho & Chuspa \\
Cóndor & Guanaco \\
Coto & Coca (derivado de cocal) \\
Cumbres & Llama \\
Inca (inga) & Pampa (derivado de pampero) \\
Mate & Poroto \\
Papa (derivado de papa seca) & Potosino \\
Poro & Puma \\
Tambo (derivado de tambero) & Taquia \\
Zapallo & \\
\hline
\end{tabular}

(Agostinho de La Torre 1999, p. 51)

No obstante, ambas lenguas presentan ciertos rasgos fonéticos y algunas estructuras morfológicas semejantes, lo mismo que un gran número de palabras comunes, por lo que no es fácil deslindar los términos aimaras de los quechuas, puesto que algunas voces existen en las dos lenguas indígenas.

\subsection{Variación en el nivel sociolingüístico}

La variación en el nivel sociolingüístico ha sido ampliamente estudiada por Caravedo, quien publica su investigación en el libro Sociolingüística del español de Lima (1990). En dicha obra, el autor manifiesta que en los últimos años se ha venido acrecentando el interés por estudiar los grandes focos urbanos como fenómenos 
sociolingüísticos que favorecen, en razón de su complejidad, la variación de los sistemas lingüísticos.

La ciudad de Lima posee características particulares debido al centralismo económico, político y social que ha estimulado el proceso migratorio de habitantes provenientes de todos los lugares del país: de las zonas andinas, amazónicas y también de las propias zonas costeñas aledañas y lejanas que constituyen provincias menores en importancia que la capital. Para esta autora, en el ámbito lingüístico, la diversidad cultural viene acompañada del contacto y del conflicto de lenguas diversas, tipológicamente muy distantes, como lo son el español y el quechua o el aimara. Se puede suponer que se produce la mutua influencia entre lenguas y la convergencia de diferentes modalidades dialectales del español.

Caravedo (1990), en su investigación sociolingüística, identifica los diferentes grupos en el orden de sus espacios originarios: primero, a su condición de migrantes y no migrantes; segundo, a las diferencias entre las distintas comunidades de migrantes, incluso separadas lingüísticamente por la posesión de lenguas distintas; por último, se detiene en las interacciones entre los grupos y su proceso de adaptación al nuevo espacio comunicativo.

Con respecto a lo anterior, los hablantes limeños singularizan a algunos migrantes a partir de muchos elementos que pueden ser físicos, raciales o lingüísticos. Estos fenómenos resultan notorios en el caso de las personas originarias de las zonas andinas, quienes hablan otra lengua y provienen de un medio mayormente rural, por lo que no pueden adaptarse con facilidad a las exigencias del mundo urbano. A causa del centralismo, la superioridad política y cultural de la ciudad de Lima, respecto de las otras zonas peruanas, contribuye a la configuración de una escala social que valora de forma jerárquica la procedencia geográfica del individuo y asigna un lugar inferior a lo considerado no limeño. Los términos "provinciano" y "serrano" surgen, peyorativamente, para singularizar y separar a otros grupos. En la valoración social, lo andino ocupa el último lugar, después de lo amazónico y de lo costeño. Tales caracterizaciones se trasladan al plano lingüístico, tal como lo evidencian Escobar y otros, cuando afirman:

No hay duda que desde el siglo XVI se ha mantenido una jerarquización y que en virtud de ella al castellano corresponde el nivel alto, mientras al quechua, como a las lenguas vernáculas, corresponden los niveles más bajos y menos apreciados de la realidad lingüística y social peruana (1975, p. 63). 
Por su parte, Santisteban y otros (2008, p. 103) procuran el fortalecimiento del quechua a partir de un diagnóstico sociolingüístico, en el que afirman que los peruanos admiten el quechua como lengua materna; sin embargo, prevalece el uso del español en ámbitos formales y públicos; existe así una situación de diglosia, debido a que el quechua posee mayor presencia en espacios relacionados con el mundo andino.

No obstante, para comprender la complejidad sociolingüística de la ciudad de Lima, Caravedo (1990, p. 30) averigua el modo de interacción e influencia de los grupos entre sí, en la cual establece una separación, referida a la "comunicación horizontal" entre el sector popular limeño y el migrante, y la "comunicación vertical" del sector culto con los migrantes. Es en esta última donde se manifiesta la cuestión valorativa en algunos aspectos lingüísticos que actúan como indicadores sociovalorativos de los individuos que la utilizan, y pueden ser positivos o negativos (formas estigmatizadas).

En el plano fonético, por ejemplo, algunas consecuencias de la comunicación vertical y de sus manifestaciones en la valoración de las formas se reflejan en procesos como la asibilación de las vibrantes. Aunque no solo los grupos andinos asibilan, esta modalidad en ciertas posiciones -intervocálica o inicial- referidas normalmente a la vibrante múltiple, se atribuye a los grupos andinos o no costeros, con la subsecuente subvaloración de la forma. En consecuencia, los grupos que asibilan tratan de evitar esa forma cuando se colocan ante un hablante costeño y en una situación formal, al producir un sonido retroflejo o una vibrante simple donde se espera la vibrante múltiple (Caravedo, 1990).

Por otro lado, la comunicación horizontal posibilita el paso de formas consideradas andinas a las modalidades de las clases populares originarias de la capital, por esto resulta difícil separar las formas andinas puras de las usadas por otros grupos populares, pues muchos de los fenómenos considerados andinos se encuentran con diferente intensidad en los grupos populares limeños, e incluso algunos, como el doble posesivo "en su casa de Juan" se presentan en los grupos de clase media. Sin embargo, existen usos más resistentes a la absorción, como la confusión vocálica, característica de los grupos andinos. En general, los usos que se desplazan con mayor facilidad parecen los más compatibles con las posibilidades variables del sistema español, independientemente de la procedencia regional (Caravedo, 1990, p. 31). 
La autora concluye que los procesos extendidos en todos los grupos sociales de la ciudad de Lima no generan valoraciones negativas. Sin embargo, existen formas, claramente estigmatizadas, ante las cuales los hablantes desarrollan mecanismos de control, e incluso de modificación, pero hay que tener en cuenta que los sistemas valorativos no son uniformes dentro de la comunidad lingüística. Una perspectiva sociolingüística adecuada debe establecer las relaciones internas entre la intensidad lingüística y extralingüística de los procesos (Caravedo, 1990, pp. 218-219).

\section{Conclusiones}

Con respecto a la situación histórica de sede virreinal, diversos autores atribuyen al español peruano una cercanía con la tradición etimológica del español. Tal idea la confirma Malmberg (1970) cuando asevera: "la situación colonial explica el hecho de que el español peruano sea, todavía hoy, el habla hispanoamericana más cercana a la norma lingüística castellana" (p. 140)

No obstante, el español de Perú, debido a sus diferencias sociales, culturales y geográficas, posee diversos rasgos lingüísticos (fonéticos - fonológicos y morfosintácticos, entre otros) que manifiestan singularidad en el habla de sus habitantes. Además, se debe tener presente el contacto intenso y prolongado entre el español y las lenguas indígenas como el quechua y aimara, cuya influencia de sustrato se evidencia, principalmente, en el léxico del español peruano, en especial con los términos asociados a la flora y fauna. En relación con el nivel sociolingüístico, Caravedo (1990) estudia los procesos migratorios de la ciudad de Lima, y concluye que muchos de los fenómenos lingüísticos extendidos en todos los grupos sociales de la ciudad no generan valoraciones negativas; sin embargo, existen algunas formas estigmatizadas.

En la revisión bibliográfica de este estudio no se encontraron investigaciones sobre la variación en el nivel pragmático - discursivo del español de Perú, debido a que en la historia de la dialectología es el nivel de la lengua menos estudiado, por la dificultad de establecer rasgos lingüísticos diferenciadores, según zonas dialectales. Al respecto, Caravedo (citado en Alvar, 2000) confirma tal aseveración cuando menciona: "falta, sin embargo, explorar el grado de penetración de los usos en las distintas modalidades y grupos en la situación de contacto, a partir de un análisis más profundo del uso de las formas en la dimensión pragmático discursiva" (p. 168). 
Por último, es importante destacar que los estudios bibliográficos y descriptivos, como el presente, tienen la finalidad de aportar en la revitalización de las lenguas indígenas, dado el riesgo de su extinción, con ello se pretende salvaguardar el patrimonio lingüístico y cultural de América. Por consiguiente, el análisis detallado acerca de todos los niveles del español de Perú (la variación fonético - fonológica, morfosintáctica, léxica y sociolingüística) proporciona información relevante sobre propiedades particulares (por ejemplo, la influencia de las lenguas indígenas quechua y aimara), lo cual podrían interesar en futuras investigaciones lingüísticas de este tipo; además, deben ser del conocimiento de sus hablantes nativos, dado que son ellos los llamados a involucrarse en el estudio de sus propias lenguas, lo anterior, con el fin de preservar sus idiomas y, por ende, su grupo cultural. 


\section{Referencias}

Agostinho de la Torre, M. (1999). Vocabulario histórico en relatos geográficos del siglo XVIII (Virreinato del Perú). Zaragoza: Hispánica Helvética.

Alvar, M. (2000). Manual de dialectología hispánica. El español de América. Barcelona: Editorial Ariel.

Caravedo, R. (1982). Constricciones contextuales del español hablado en Lima. El caso de /s/. En Actas del I Congreso Internacional sobre el Español de América. Academia Puertorriqueña de la Lengua Española. San Juan, Puerto Rico.

Caravedo, R. (1990). Sociolingüística del español de Lima. Lima: Fondo Editorial de la Pontificia Universidad Católica del Perú.

De Grada, G. (1994). Español de América, español de África. Madrid: Gredos.

Escobar, A., Alberti, G. y Matos Mar, J. (1975). Perú ¿país bilingüe? Lima: Instituto de Estudios Peruanos. Fontanella de Weinberg. (1993). El español de América. Madrid: MAPFRE.

Haring, C. H. (1990). El imperio español en América. Traducción de Adriana Sandoval. México, D. F.: Alianza Editorial Mexicana.

Kany, Ch. (1994). Sintaxis Hispanoamericana. Traducción de Martín Blanco Álvarez. Madrid: Gredos.

Lipski, J. (1994). El español de América. Madrid: Cátedra.

Malmberg, B. (1970). La América hispanohablante. Madrid: Editorial ISTM.

Martínez López, J. A. (1998). Algunas apreciaciones lingüísticas sobre el español peruano en los personajes de Los ríos profundos de J. M. Arguedas. En Revista de Filología y Lingüística de la Universidad de Costa Rica, 26(1), 121-153.

Quesada Pacheco, M. A. (2000). El español de América. Cartago: Editorial Tecnológico de Costa Rica.

Rivarola, J. L. (1999). Para la historia del español de América: parodias de la "lengua de indio" en el Perú (SS. XVII - XIX). Asociación de Lingüística y Filología de América Latina. Actas del VIII Congreso Internacional. Universidad Nacional de Tucuma. Argentina.

Santisteban, H. y otros. (2008). Diagnóstico sociolingüístico para el fortalecimiento del quechua. Lima: Tarea Asociación de Publicaciones Educativas.

Vaquero de Ramírez, M. (1995). El español de América I. Pronunciación. Madrid: Arco Libros.

Vaquero de Ramírez, M. (1998). El español de América II. Morfosintaxis y léxico. Madrid: Arco Libros. 